\title{
Multi-Tissue DNA Methylation Remodeling at Mitochondrial Quality Control Genes According to Diet in Rat Aging Models
}

\author{
Patrizia D'Aquila ${ }^{1, *}$, Francesco De Rango ${ }^{1, *}$, Francesco Guarasci ${ }^{2}$, Maurizio Mandalà ${ }^{1}$, \\ Andrea Corsonello ${ }^{2} \mathbb{D}$, Dina Bellizzi ${ }^{1,+}$ and Giuseppe Passarino ${ }^{1,+}$ \\ 1 Department of Biology, Ecology and Earth Sciences, University of Calabria, 87036 Rende, Italy; \\ m.mandala@unical.it (M.M.); dina.bellizzi@unical.it (D.B.); g.passarino@unical.it (G.P.) \\ 2 Italian National Research Center on Aging (IRCCS INRCA), 87100 Cosenza, Italy; \\ guarasci.francesco@gmail.com (F.G.); a.corsonello@inrca.it (A.C.) \\ * Correspondence: d_patrizia2002@yahoo.it (P.D.); f.derango@unical.it (F.D.R.); Tel.: +39-0984492934 (P.D.); \\ +39-0984492933 (F.D.R.) \\ + Joint senior authors.
}

Received: 31 January 2020; Accepted: 8 February 2020; Published: 12 February 2020

\begin{abstract}
An adequate mitochondrial quality control system ensures the maintenance of a healthy mitochondrial pool so as to slow down the progressive accumulation of damage affecting mitochondrial function during aging and diseases. The amount and quality of nutrients availability were demonstrated to induce a process of bioenergetics adaptation by influencing the above system via epigenetic modifications. Here, we analyzed DNA samples from differently-aged rats fed a standard or low-calorie diet to evaluate tissue-specific changes in DNA methylation of CpG sites falling within Polg, Polg2, Tfam, Fis1, and Opa1 genes. We found significant changes according to age and tissue type and the administration of the low-calorie diet is responsible for a prevalent increase in DNA methylation levels. Particularly, this increase was more appreciable when this diet was administered during adulthood and at old age. Regression analysis demonstrated that DNA methylation patterns of the analyzed genes were negatively correlated with their expression levels. Data we obtained provide the first evidence about changes in DNA methylation patterns of genes involved in the mitochondrial biogenesis in response to specific diets and demonstrated that epigenetic modifications are involved in the modulation of mitochondrial dynamics driven by age and nutrition.
\end{abstract}

Keywords: DNA methylation; mitochondrial dynamics; mitochondrial fission; mitochondrial fusion; mitochondrial biogenesis; aging; nutrition

\section{Introduction}

The progressive accumulation of functional impairments in mitochondrial function has been widely recognized as one of the main hallmarks of aging and age-related diseases [1,2]. The age-related mitochondrial decline is partially due to a failure in the fine-tune coordination of mitochondrial turnover mechanisms that regulate the morphology, the size and the number of functional mitochondria under a wide variety of both physiological and non-physiological conditions [3-5]. These mechanisms include the increase of mitochondrial mass (biogenesis), the division of a mitochondrion in two or more daughter organelles (fission), the merging of healthy and damaged mitochondria (fusion) and the selective clearance of damaged mitochondria via the autophagic pathway (mitophagy) $[4,6,7]$. The accumulation of dysfunctional mitochondria leads the drop of mitochondrial energy production, the loss of mitochondrial membrane potential, the burst of damage to cellular macromolecules by 
mitochondrial Reactive Oxygen Species (ROS), the dysregulation of calcium homeostasis, and alteration in cell growth and death [8]. It follows that the progressive loss in mitochondrial quality control system is decisive in driving toward the overall physiological unbalance typical of aging process $[4,5]$.

Moreover, studies on mitochondrial integrity and function have revealed that mitochondrial architecture undergoes to a process of bioenergetics adaptation in response to particular conditions, including changes in energy demand or nutrient supply, to prevent or maximize Adenosine triphosphate (ATP) synthesis [9,10]. Nutrient excess was demonstrated to induce a shift towards mitochondrial fission and to inhibit mitophagy, thus, increasing ROS levels and the pool of dysfunctional mitochondria [9,11-14]. Conversely, nutrient scarcity was found to be associated with mitochondrial fusion and elongation [14,15]. In addition, lipid oversupply can alter mitochondrial dynamics [16]. In particular, in skeletal muscle, lipid oversupply negatively influences the expression of genes involved in mitochondrial biogenesis such as members of mitochondrial complex I and II as well as peroxisome proliferator-activated receptor gamma coactivator 1-alpha (PGC1 $\alpha$ ) and peroxisome proliferator-activated receptor gamma coactivator 1-beta (PGC1 $\beta)$, key regulators of mitochondrial DNA replication [17-19]. This evidence was recently confirmed by $\mathrm{Xu}$ et al., who reported a decrease in mitochondrial number, ATP synthesis and mitochondrial membrane potential in skeletal muscle of 8- and 16-week old mice fed a high-fat diet [20]. Furthermore, a high-fat diet has been demonstrated to downregulate the protein levels of Sirtuin 3 (SIRT3), deacetylases that regulate not only mitochondrial metabolism, but also a number of regulators of mitochondrial function [21]. In vitro experiments also demonstrated that $\mathrm{C} 2 \mathrm{C} 12$ cells treated with ceramide and palmitic acid showed increased mitochondrial fission, loss in ATP synthesis and increased oxidative stress [22,23]. Moreover, it was demonstrated the shift towards mitochondrial biogenesis in the skeletal muscle of mice fed with a high-fat diet supplemented by Omega-3 polyunsaturated fatty acids (PUFAs) such as eicosapentaenoic (EPA) docosahexaenoic (DHA) acids. Mitochondrial abundance, associated to the upregulation of PGC1 $\alpha$ and Nuclear Respiratory Factor 1 (NRF1) transcription factors resulted also in the increase of fatty acid oxidation, suggesting the favorable effect of this diet in counteracting lipotoxicity and the onset of insulin resistance [24,25]. Overall promotion of mitochondrial fusion by omega-3PUFAs was also widely demonstrated [26-29]. In particular, Casanova et al. (2014) demonstrated that DHA also influences mitochondrial morphology since cultured myocytes displayed giant and elongated mitochondria and the downregulation of fission-promoting genes, including Fis1 and Drp1 [29]. Consistent results were observed in skeletal muscle and liver of Wistar rats [27,28].

If it has been largely demonstrated that caloric restriction (CR), namely the reduction of caloric intake (from 10 to $40 \%$ ), exerts beneficial effects on the extension of lifespan in numerous model organisms; less clear is the evidence about its putative role on mitochondrial dynamics, likely because of the heterogeneity of the degree of energy restriction, the duration of treatment and the tissue type in both humans and model organisms. Alongside studies demonstrating that CR promotes biogenesis, many others could not find any significant correlation between the diet and mitochondrial mass, fusion and fission [30-37].

Calorie restriction, micronutrients supplementation as well as fasting and fasting-mimicking diets were recently demonstrated being responsible for the massive intracellular reprogramming network occurring in aging across a wide variety of living organisms. This reprogramming is mainly mediated by epigenetic mechanisms and result in significant structural changes in chromatin that ultimately result in the alteration of gene expression [38-43].

Given the pivotal role of mitochondria both in energy metabolism and in producing substrates for DNA methylation and histone modifications as well as the ability of nutrition to induce epigenetic remodeling, we explored in rats whether changes in eating habit during life were able to modulate the methylation status of candidate genes involved in mitochondrial fusion/fission and biogenesis processes. To this purpose, we searched for tissue-specific differences in the methylation status of Cytosine-phosphate-Guanine $(\mathrm{CpG})$ islands falling within pivotal genes previously found to be 
involved in mitochondrial biogenesis, fusion and fission (Polg, Polg2, Tfam, Fis1 and Opa1) in DNA samples from differently aged rats fed with standard or low-calorie diet.

\section{Materials and Methods}

\subsection{Animals}

Experiments were performed on Sprague-Dawley rats breeding locally in the animal care facility of the University of Calabria (Italy). Animals ( $n=3$ for experimental condition) were housed in light (12:12 $\mathrm{h}$ light-dark cycle) and temperature $\left(22^{\circ} \mathrm{C}\right)$ controlled rooms with free access to food (ssniff diet V1535, Ferdinand-Gabriel-Weg 16 D-59494 Soest, German, metabolizable energy 3.057 kcal/kg) and water. The rats were divided into two groups: the first (control group) was fed with standard diet up to 27,36 , and 96 weeks old, the second (treated group) was fed with low-calorie diet (60\% of the intake) for a total period of 6 months started at the age of 3 weeks, 12 weeks and 72 weeks.

Water and food intake were recorded every other day while body mass was recorded monthly. Animals were euthanized with inhalation of Diethyl ether followed by cervical transection and immediately sacrificed. All procedures were conducted according to the European Guidelines for the care and use of laboratory animals (Directive 2010/63/EU) and in accordance with Italian law; the study was authorized with authorization number 295/2016-PR by the Ethical committee of the Ministry of Health.

\subsection{DNA and mRNA Extraction}

$500 \mu \mathrm{L}$ of rat peripheral blood was drawn by cardiac puncture and kept on ice in the presence of DNA extraction buffer (10 mM Sodium chloride ( $\mathrm{NaCl}), 20 \mathrm{mM}$ Tris-Buffer (Tris- $\mathrm{HCl}) \mathrm{pH}$ 8.0, $1 \mathrm{mM}$ Ethylenediaminetetraacetic acid (EDTA). Heart, liver, kidney, brain, lung and a vessel (mesenteric artery) were excised, placed in cold 4-(2-hydroxyethyl)-1-piperazineethanesulfonic acid (HEPES) physiological saline solution (HEPES-PSS pH7.4, $141.8 \mathrm{mM} \mathrm{NaCl}, 4.7 \mathrm{mM}$ Potassium chloride (KCl), $1.7 \mathrm{mM}$ Magnesium sulfate $\left(\mathrm{MgSO}_{4}\right), 0.5 \mathrm{mM}$ EDTA, $2.8 \mathrm{mM}$ Calcium chloride $\left(\mathrm{CaCl}_{2}\right), 10 \mathrm{mM}$ HEPES, $1.2 \mathrm{mM}$ Potassium phosphate monobasic $\left(\mathrm{KH}_{2} \mathrm{PO}_{4}\right), 5 \mathrm{mM}$ Glucose), weighed and thoroughly homogenized in presence of DNA extraction buffer. Then, 10\% sodium dodecyl sulfate (SDS) and 10 $\mathrm{mg} / \mathrm{mL}$ of proteinase $\mathrm{K}$ were added to all samples, which were then vigorously vortexed and incubated at $37^{\circ} \mathrm{C}$ for $48 \mathrm{~h}$ with periodical mixing. Genomic DNA was obtained by phenol/chloroform purification.

Total RNA from peripheral blood was obtained from $500 \mu \mathrm{L}$ of samples by using the QIAamp RNA Blood Mini kit, according to manufacturer's protocol. $50 \mathrm{mg}$ of frozen heart, liver and kidney were excised and homogenized in buffer RTL and total RNA was purified using RNeasy Mini Kit (Qiagen, Hilden, Germany) according to manufacturer's recommendations and RNA samples were treated with DNA-free DNase to remove any residual genomic DNA contamination.

The DNA and RNA concentration and purity were determined spectrophotometrically and purity of the sample evaluated using the $260 / 280 \mathrm{~nm}$ absorbance ratio.

\subsection{Primer Design for EpiTYPER Assay}

Polymerase chain reaction (PCR) primers for the genes of interest were designed using Sequenom's EpiDesigner (Sequenom, Inc., San Diego, CA, USA) software (Table S1). They do not contain CpGs, amplify both methylated and unmethylated sequences equally, and, due to degradation of DNA during bisulfite conversion, delimit amplicon of size below $300 \mathrm{bp}$ to increase the amplification success rate, thus, covering as many CpGs as possible. For this reason, the regions of interest of Opa1 and Fis1 genes were amplified in adjacent and overlapping three and two amplicons, respectively.

A T7-promoter tag (CAGTAATACGACTCACTATAGGGAGAAGGCT) was added to the reverse primers for the in vitro T7 transcription and a 10-mer tag sequence (AGGAAGAGAG) was added to the forward primers to balance the PCR primer length. 


\subsection{Bisulfite Treatment and PCR Conditions}

Bisulfite conversion of each DNA sample was performed using the EZ-96 DNA Methylation-Gold kit (Zymo Research, Euroclone, Milan, Italy), according to the manufacturer's protocol. Briefly, $1 \mu \mathrm{g}$ of genomic DNA was added to $130 \mu \mathrm{L}$ of CT conversion reagent in a final volume of $150 \mu \mathrm{L}$. The mix was incubated at $98^{\circ} \mathrm{C}$ for $10 \mathrm{~min}$ and, successively, at $64^{\circ} \mathrm{C}$ for $2.5 \mathrm{~h}$. After adding $400 \mu \mathrm{L}$ of M-binding buffer to the wells of the silicon-A binding plate, each sample was loaded into the wells and centrifuged at $3000 \times g$ for $5 \mathrm{~min}$. After adding $400 \mu \mathrm{L}$ of M-wash buffer to the wells and centrifugation at $3000 \times g$ for $5 \mathrm{~min}, 200 \mu \mathrm{L}$ of M-desulfonation buffer was added to each well and incubated at room temperature for $20 \mathrm{~min}$. Then, the solution was removed by centrifugation at $3000 \times g$ for 5 min and the wells were washed twice with $400 \mu \mathrm{L}$ of M-wash buffer. Deaminated DNA was eluted in $30 \mu \mathrm{L}$ of M-elution buffer. The PCRs were carried out in a total volume of $5 \mu \mathrm{L}$ using $1 \mu \mathrm{L}$ of bisulfite-treated DNA, EpiTaq PCR buffer $1 X 0.4 \mu \mathrm{M}$ of each primer, $0.3 \mathrm{mM}$ Deoxynucleotide (dNTP) mixture, $2.5 \mathrm{mM}$ of $\mathrm{MgCl}_{2}$, and $0.005 \mathrm{U}$ TaKaRa EpiTaq hot-start (HS) (TaKaRa, Diatech Lab Line, Milan, Italy). The thermal profile used for the reaction included a 4-min heat activation of the enzyme at $95^{\circ} \mathrm{C}$, followed by 45 cycles of denaturation at $94{ }^{\circ} \mathrm{C}$ for $20 \mathrm{~s}$, annealing at optimal temperature for each primer pair (Table S1) for $30 \mathrm{~s}$, extension at $72{ }^{\circ} \mathrm{C}$ for $1 \mathrm{~min}$, then one cycle at $72{ }^{\circ} \mathrm{C}$ for $3 \mathrm{~min} .0 .5 \mu \mathrm{L}$ of each PCR product was electrophoresed on $1.5 \%$ agarose gel to confirm successful PCR and amplification specificity.

\subsection{Dephosphorylation of Unincorporated Deoxynucleosidetriphosphates and in vitro Transcription and RNaseA Cleavage}

Unincorporated dNTPs in the amplification products were dephosphorylated by adding $1.7 \mu \mathrm{L}$ DNase free water and $0.3 \mu \mathrm{L}(0.5 \mathrm{U})$ shrimp alkaline phosphatase (SAP) (Sequenom, Inc., San Diego, CA, USA). Each reaction was incubated at $37^{\circ} \mathrm{C}$ for $40 \mathrm{~min}$, and SAP was then heat inactivated at $85^{\circ} \mathrm{C}$ for $5 \mathrm{~min}$. Subsequently, samples were incubated at $37^{\circ} \mathrm{C}$ for $3 \mathrm{~h}$ with $5 \mu \mathrm{L}$ of T-cleavage reaction mix (Sequenom), containing 3.21 $\mu \mathrm{L}$ RNAse-free water, $0.89 \mu \mathrm{L} 5$ X T7 polymerase buffer, $0.22 \mu \mathrm{L}$ T-cleavage mix, $0.22 \mu \mathrm{L} 100 \mathrm{mM}$ DTT, $0.40 \mu \mathrm{L}$ T7 RNA polymerase and $0.06 \mu \mathrm{L}$ RNase A, for concurrent in vitro transcription and base-specific cleavage. The samples of cleaved fragments were then diluted with 20 $\mu \mathrm{L}$ of water. Conditioning of the cleavage reaction was carried out by adding $6 \mathrm{mg}$ of clean resin.

\subsection{Mass Spectrometry}

$10 \mathrm{nl}$ of the resultant cleavage reactions were spotted onto silicon matrix preloaded chips (Spectro-CHIP; Sequenom) using the MassARRAY nanodispenser (Sequenom) and analyzed using the MassARRAY Compact System matrix-assisted laser desorption/ionization-time-of-flight mass spectrometer (MALDI-TOF) (Sequenom). The spectra's methylation ratios were calculated using EPITYPER software v1.0 (Sequenom). The method yields quantitative results for each of the sequence-defined analytic units referred as CpG units, which may contain either one individual CpG site or an aggregate of CpG sites. Triplicate independent analyses from sodium bisulfite-treated DNA samples were undertaken. The effectiveness of the entire experimental procedure was assessed by analyzing as control CpGenome Universal Unmethylated DNA (Chemicon, Millipore, Nuremberg, Germany) and CpGenome Universal Methylated DNA (Chemicon) in serial mixtures of methylated and unmethylated products, with $10 \%$ methylation increments. Data quality control and filtering were carried out by the removal of the CpG dinucleotides whose measurement success rate was $<90 \%$. Poor-quality and non-valuable data for the quantitative methylation of each CpG unit measured by MALDI-TOF-MS were excluded.

\subsection{Expression Profile Analysis of rat Polg, Polg2, Tfam, Fis1, and Opa1 Genes}

Reverse transcriptase-PCRs (RT-PCR) were carried out using the RevertAid RT Kit (Thermo Fisher Scientific, Milan, Italy). First, an RT mix including 500 ng of total RNA and $1 \mu L$ of Oligo(dT)18 primers was preheated at $65{ }^{\circ} \mathrm{C}$ for $5 \mathrm{~min}$. Then, the reaction was carried out in a $20 \mu \mathrm{L}$ final volume 
containing $1 \mathrm{X}$ reaction buffer, $20 \mathrm{U}$ of RiboLock RNase inhibitor, $1 \mathrm{mM}$ of dNTP mix, and $200 \mathrm{U}$ of RevertAid M-MuLV RT reverse transcriptase. The mix was incubated at for $60 \mathrm{~min}$ at $42{ }^{\circ} \mathrm{C}$ and, successively, at $70^{\circ} \mathrm{C}$ for $5 \mathrm{~min}$ to inactivate the reverse transcriptase. The cDNAs obtained were then used as a template for real-time PCRs carried out using the SYBR Green qPCR Master Mix (Promega, Milan, Italy) in a StepOne Plus machine (Applied Biosystems, Milan, Italy). Forward and reverse primers were reported in Table S2.

The final PCR mixture $(15 \mu \mathrm{L})$ contained $1 \mu \mathrm{L}$ of cDNA, SensiFAST SYBR Hi-ROX Mix 1X (Bioline, London, UK) and $0.2 \mu \mathrm{M}$ of each primer. The thermal profile used for the reaction included a 2-min heat activation of the enzyme at $95{ }^{\circ} \mathrm{C}$, followed by 35 cycles of denaturation at $95{ }^{\circ} \mathrm{C}$ for $15 \mathrm{~s}$ and annealing/extension at $60^{\circ} \mathrm{C}$ for $60 \mathrm{~s}$, followed by melt analysis ramping at $60-95^{\circ} \mathrm{C}$. All measurements were taken in the log phase of amplification. Negative controls (in which water instead of cDNA was added) were also run in each plate. StepOne Software V 2.0 was used to analyze data. Gene expression values were normalized to Glyceraldehyde-3-phosphate dehydrogenase (GAPDH) gene expression, used as internal control and 27 weeks old rat samples were used as reference values (relative quantification) for the other samples.

\subsection{Quantification of mtDNA Copy Number}

ND1 and actin beta genes, representing either mitochondrial or nuclear DNA, were used in Real-time quantitative PCR reactions to quantify mtDNA copy number. The PCR mixture $(15 \mu \mathrm{L})$ consisted of $1 \mu \mathrm{L}$ of DNA (100 ng), SensiFAST SYBR Hi-ROX Mix 1X (Bioline, London, UK) and 0.2 $\mu \mathrm{M}$ of each primer. Forward and reverse primers were reported in Table S2. The thermal profile used for the reaction included a 2-min heat activation of the enzyme at $95{ }^{\circ} \mathrm{C}$, followed by 35 cycles of denaturation at $95^{\circ} \mathrm{C}$ for $15 \mathrm{~s}$ and annealing/extension at $60^{\circ} \mathrm{C}$ for $60 \mathrm{~s}$, followed by melt analysis ramping at $60-95^{\circ} \mathrm{C}$. All measurements were taken in the log phase of amplification. Negative controls (in which water instead of cDNA was added) were also run in each plate.

Standard curves for mtDNA (ND1) and actin beta were generated with normal control rats. Templates in each reaction were diluted 1:100,000, 1:10,000, 1:1000, 1:100, 1:10 and 1:1. Substrate concentrations were calculated according to the standard curves. The copy number of mitochondrial gene ND1 was normalized to the single-copy nuclear gene. Relative mtDNA copy number was calculated and expressed by using the $2-\Delta \Delta C T$ method [44].

\subsection{Statistical Analyses}

Comparisons between groups were tested using unpaired t-test and one-way analysis of variance (ANOVA) followed by Tukey's post hoc test. Normality was checked for all data before analysis. Methylation differences of at least $10 \%$ and $p$-value of $<0.05$ were considered statistically significant. Correlation analyses were performed using Pearson's correlation coefficient. The strength of the Pearson's correlation coefficients was identified as weak $r \leq 0.3$, moderate $r=0.3 \leq 0.5$ and strong $r \geq 0.5$. All statistical analyses were performed using the R system (version 3.6.1).

\section{Results}

\subsection{CpG Methylation Levels of Polg, Polg2, Tfam, Fis1, and Opa1 in Tissues from Rats of Different Ages}

We assessed age-related changes in methylation of $\mathrm{CpG}$ islands located within candidate genes involved in mitochondrial fusion/fission and biogenesis processes. by Sequenom MassARRAY EpiTYPER. Specifically, CpG islands annotations were downloaded from the UCSC genome database. Key genes regulating the above processes, such as Nrf1, Mfn1, Mfn2, Pgc1- $\alpha$ and $\beta$, were found not to have islands, hence, they have not been included in the study. The analysis was carried out in bisulfite-treated DNA samples extracted from four tissues (blood, heart, kidney and liver) of rats of 27, 36 and 96 weeks old. Following stringent quality control criteria (see Materials and Methods), the final dataset included 146 CpG sites organized in single sites or CpG units (Figure S1). We performed 
a one-way ANOVA followed by Tukey's post hoc test to investigate changes of DNA methylation levels with age. In Figure 1 for each tissue, age-associated DNA methylation levels are reported as arithmetic mean of the CpG sites of each gene. In particular, Polg and Tfam in heart showed a gain of DNA methylation in the period of life comprised between 27 and 36 weeks, but a loss of DNA methylation from 36 weeks onwards ( $p<0.001$ and $p=0.005$, respectively). Moreover, a progressive gain of DNA methylation was observable for Tfam in kidney and liver $(p<0.001$ and $p=0.01)$ and Opa1 in the liver $(p=0.008)$. Polg2 in the heart and liver exhibits an increase between 36 and 96 weeks $(p<0.001)$, Polg in liver showed a linear decline $(p<0.001)$, while Polg2 in blood $(p<0.001)$, kidney ( $p$ $=0.018)$ and Tfam $(p=0.037)$ and Opa1 in blood $(p<0.001)$ undergo a decrease in DNA methylation levels only after 36 weeks. No changes in DNA methylation according to age were observed for Polg in blood and kidney, Opa1 in blood, heart and kidney and Fis1 in all tissues analyzed.

A
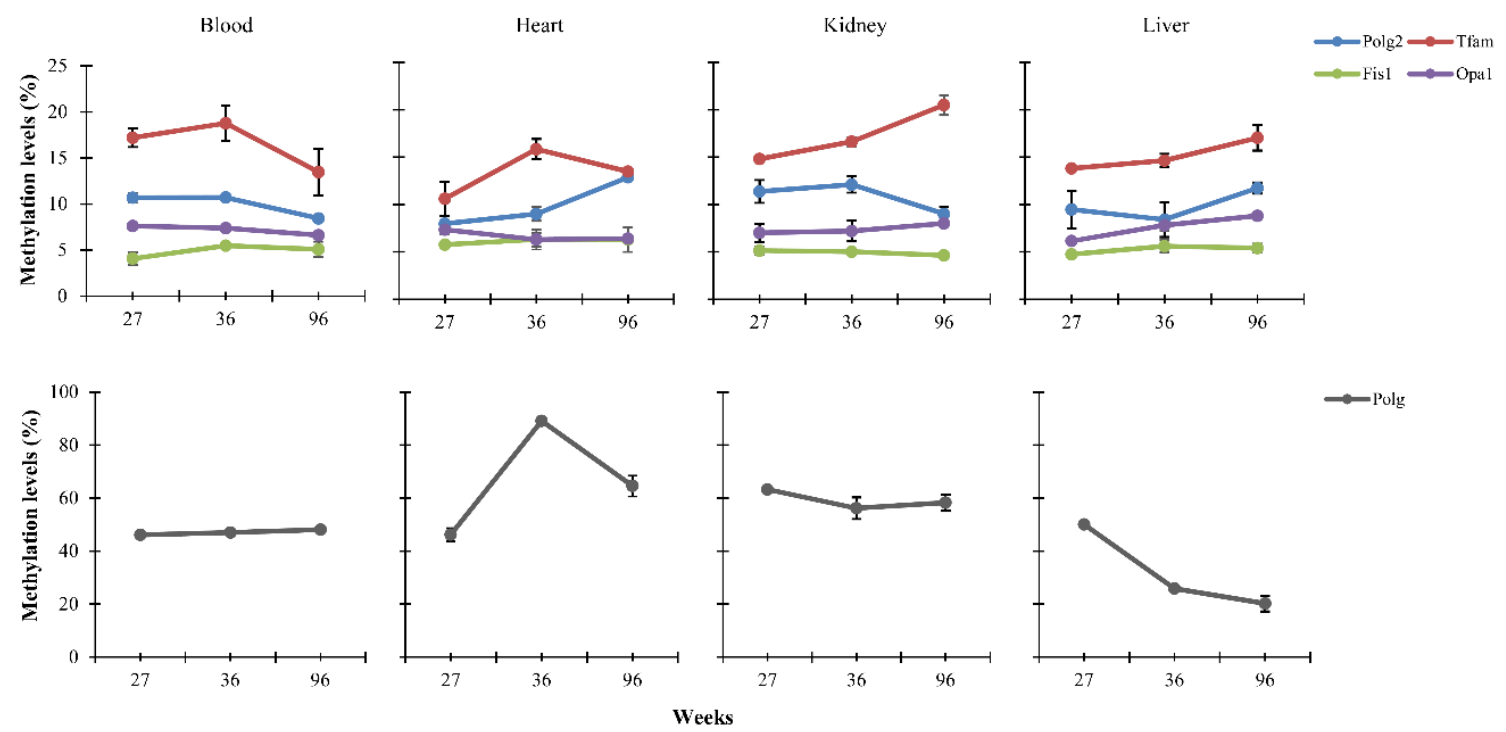

Figure 1. Age-related DNA methylation levels in blood, heart, kidney and liver of differently-aged rats. These levels are reported as arithmetic mean of the CpG sites located within Polg2, Tfam, Fis1 and Opa1 (A). Polg DNA methylation levels are reported in (B) because of their different numerical scale.

3.2. Dietary Effects on CpG Methylation Levels of Polg, Polg2, Tfam, Fis1, and Opa1 in Tissues from Rats of Different Ages

In order to investigate nutritional effects during age on DNA methylation status of Polg, Polg2, TFAM, Fis1 and Opa1 genes, quantification of CpG methylation levels were carried out in bisulfite-DNA samples extracted from the four tissues of rats of 27, 36 and 96 weeks old fed low-calorie diet for 24 weeks. As shown in Figure 2, a linear gain of DNA methylation was observable for Polg in the blood ( $p$ $<0.001)$ and heart $(p<0.001)$ and Tfam in the kidney $(p<0.001)$. This increase was also observed for Polg2 in the heart $(p<0.001)$ and kidney $(p<0.001)$ and Tfam in the heart $(p<0.001)$ up to 36 weeks of age, and then, a decrease up to 96 weeks occurs. Tfam methylation increases in the liver up to 36 weeks, then, remaining constant $(p=0.013)$. Conversely, Polg $(p<0.001)$ and Polg2 $(p=0.002)$ DNA methylation levels decrease in the liver between 27 and 36 weeks and, then, increase from 36 weeks onwards. The only negative trend is observable for Tfam $(p=0.002)$ in blood from 36 weeks onwards. No significant differences in DNA methylation levels were observed for Polg in the kidney, Polg2 in the blood and for Fis1 and Opa1 in all the tissues analyzed. 
A
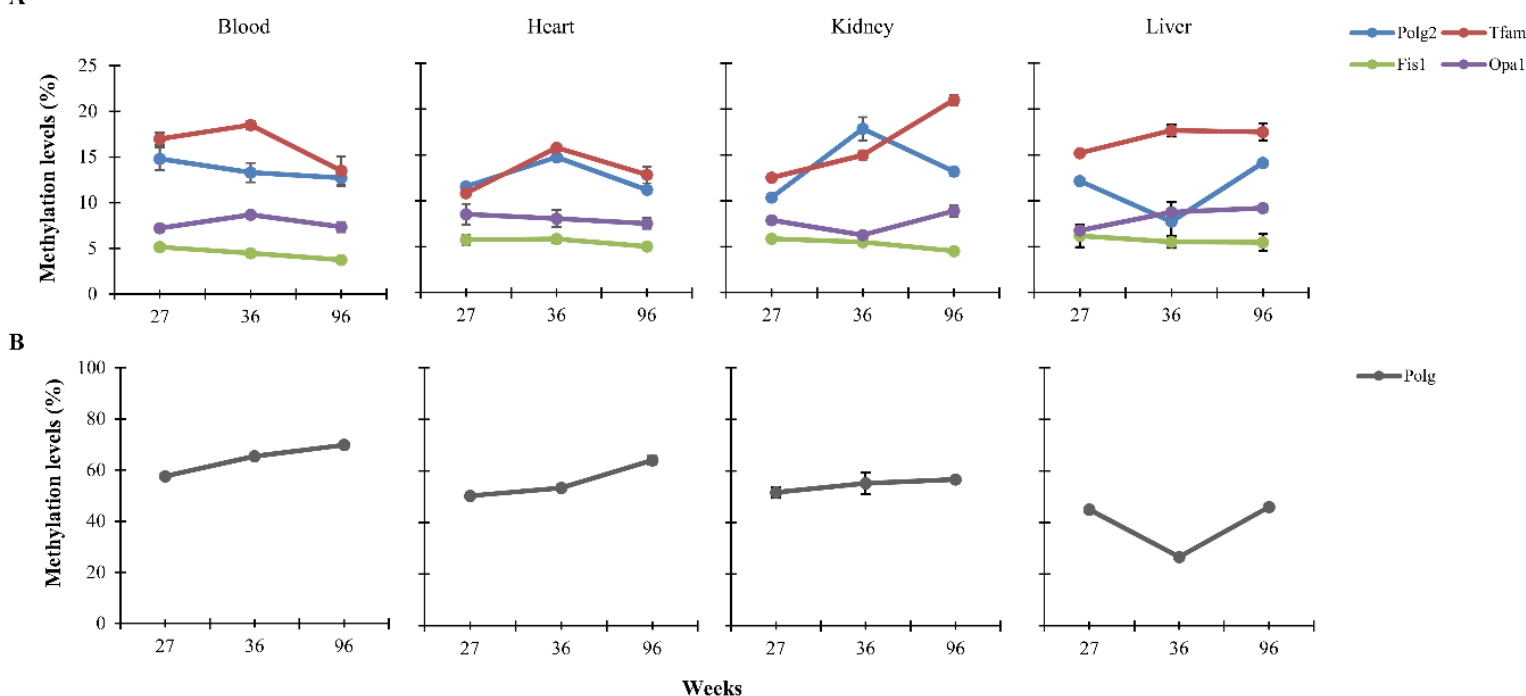

Figure 2. Age-related DNA methylation levels in blood, heart, kidney and liver of differently-aged rats fed low-calorie diet. These levels are reported as arithmetic mean of the CpG sites located within Polg2, Tfam, Fis1 and Opa1 (A). Polg DNA methylation levels are reported in (B) because of their different numerical scale.

To get the endpoint of changes in the DNA methylation in response to the nutritional regime, we compared, for each age, the mean methylation levels between the low-calorie samples with the age-matched controls. We found that diet induces a significant change in DNA methylation levels during aging. The increment and decrement percentage for each gene are shown in Figure 3 and Table S3. Fis1 and Opa1 did not show any relevant change.
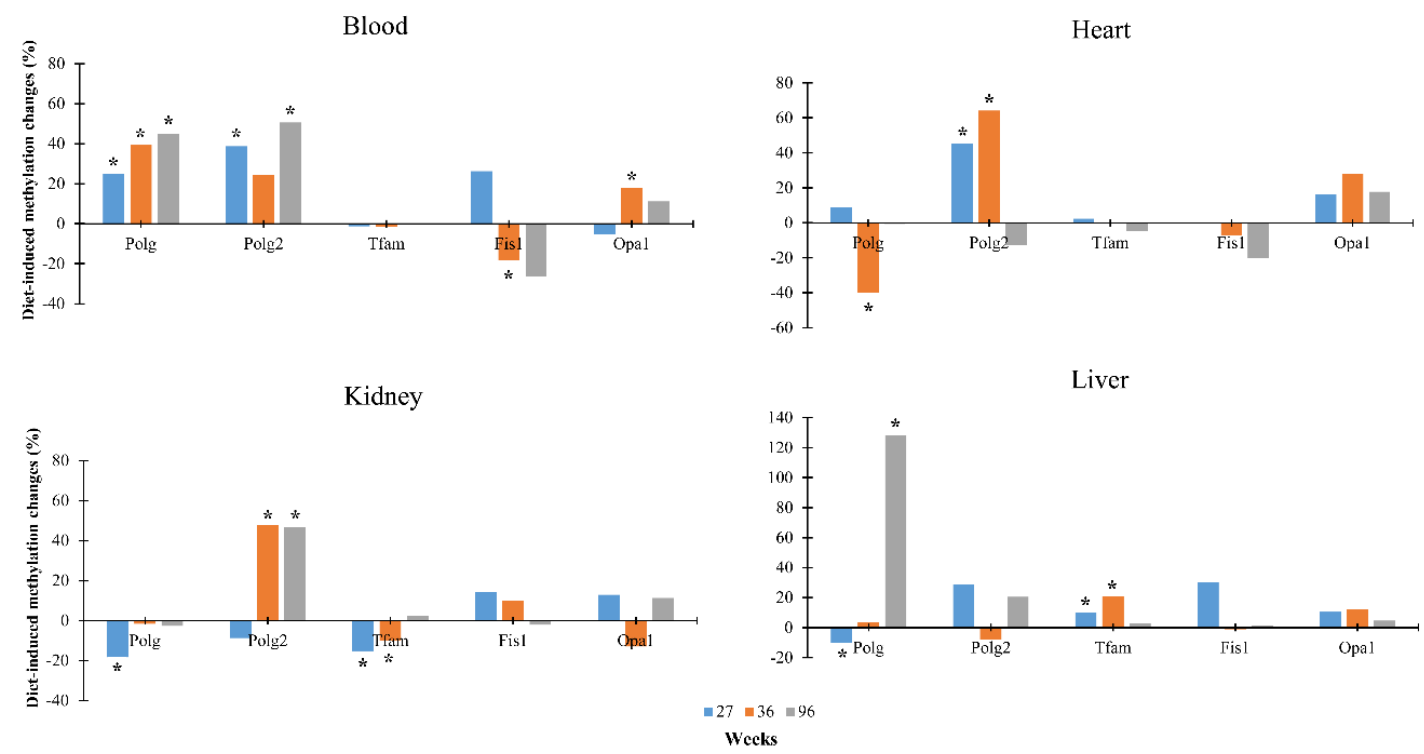

Figure 3. Diet-induced methylation changes in Polg, Polg2, Tfam, Fis1 and Opa1 genes in blood, heart, kidney and liver in differently-aged rats. ${ }^{*} p$-value $<0.05$ and changes $>10 \%$.

For clarity, we have reported in Table S4 DNA methylation values of the CpG sites of each gene used to determine the mean values reported in the analyses. 


\subsection{Correlation among Methylation, $m R N A$ Levels and mtDNA Copy Number}

To explore the functional relevance of the changes in DNA methylation of the analyzed genes, quantitative real-time PCR assays were carried out to evaluate the expression of Polg, Polg2, Tfam, Fis1 and Opa1 in blood, heart, kidney and liver samples from rats of different age and fed standard or low-calorie diet. We observed that Polg, Polg2, Tfam and Opa1 are differently expressed in both standard or low-calorie diet according to the DNA methylation changes. Conversely, Fis1 did not exhibit any significant change (Figure S2). Then, we carried out a regression analysis in order to investigate the association between the expression of Polg, Polg2, Tfam, Fis1 and Opa1 genes and the corresponding DNA methylation profiles. The analysis revealed an inverse relationship, in most cases statistically significant (Table 1).

Table 1. Pearson Correlation (R) between the Level of DNA Methylation, Polg, Polg2, Tfam, Fis1 and Opa1 Expression and mtDNA Copy Number. CI: Confidence Interval.

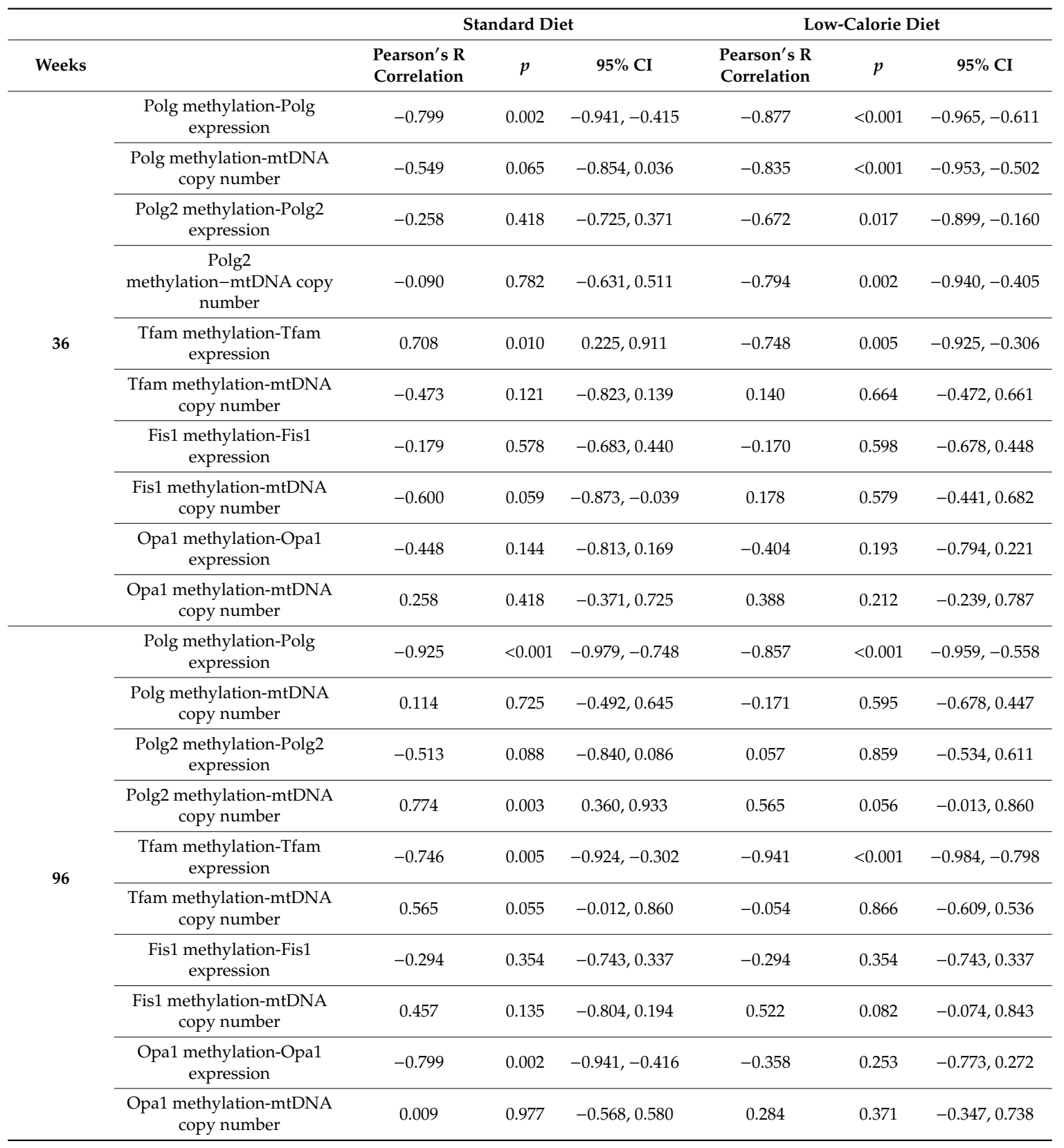


The only discrepancy for the Tfam gene at 36 weeks in standard-fed conditions (in which a significant positive relationship was observed) was due to the missing correlation between Tfam methylation and expression in the heart.

Then, we determined whether DNA methylation levels influenced the mtDNA copy number (Figure S3). Regression analysis did not show a significant correlation except for Polg2 at standard-fed conditions (96 weeks) and Polg and Polg2 at low-calorie diet (36 weeks) (Table 1).

\section{Discussion}

Understanding the molecular basis of lifespan-extending interventions is one of the most difficult and arduous challenges for researchers. In this frame, epigenetic modifications have emerged as newsworthy features given their peculiar plasticity to undergo more or less consistent changes in response to a wide range of environmental changes, including lifestyle and dietary habits. In particular, nutrient availability can regulate mitochondrial quality control system and dynamics, thus, contributing to the onset of specific physiological and pathological phenotypes. In this study, we aimed at disentangling this aspect, by elucidating changes in DNA methylation status of candidate genes involved in mitochondrial fusion/fission and biogenesis processes according to changes in nutrition habit during life.

To this purpose, we searched for tissue-specific differences in the methylation status of CpG islands falling within candidate genes involved in mitochondrial biogenesis, fusion and fission in DNA samples extracted from differently aged rats fed standard or low-calorie diet. Our findings indicated peculiar DNA methylation patterns for each analyzed gene; thus, typical for each tissue from youth to old age is that the same gene shows different variation trends depending on the tissue under examination except for Fis1.

The findings here presented, consistent with literature data, demonstrated that an inverse relationship between DNA methylation and the expression of the associated genes occurs with age, thus providing the functional effects of the observed methylation patterns [45,46]. As demonstrated by bioinformatics analysis, most of the CpG sites undergoing to significant changes overlap with Sp1, YY1, NRF-1 and AP-1, which are methylation-sensitive transcription factors and could regulate the mitochondrial fusion/fission and biogenesis processes. These observations lead us to retain that the progressive impairment of the above processes, widely described during aging process, is mostly thought to be ascribed to their epigenetic regulation during the lifetime according to the specific needs of tissues [47-50]. Of note, the positive correlation between Tfam gene methylation and its expression we observed at 36 weeks seems outlandish. This discrepancy is attributable to the high levels of methylation of the gene in the heart which create a bias in the analysis. As also discussed by Barazzoni et al., likely, the peculiar characteristics of the heart tissue and its contractile activity as well as its age-associated oxidative alteration may unavoidably regulate the molecular mechanisms underlying mitochondrial gene expression [51]. Since the DNA methylation levels have been determined as the mean of the methylation values at the CpG sites of each gene, we are confident that they represent the overall methylation status of the whole region analyzed. The significant correlation between methylation and gene expression confirms our assumption.

While methylation appears to influence gene expression, it does not unequivocally affect the mtDNA copy number since we found this association only in a few experimental conditions. These observations take place in a context of scarce and controversial literature in which a series of factors, including age, degree of cellular and tissue differentiation and type represent just a few of the factor involved in the regulation of mitochondrial DNA copy number. To confirm this, the findings of this paper reveal an association between DNA methylation and mtDNA copy number limited to Polg2 at 96 weeks and Polg and Polg2 at 36 weeks at standard and low-calorie diet, respectively.

When compared to the standard diet, the administration of the low-calorie diet results responsible for a prevalent increase in DNA methylation levels of the all analyzed genes and tissues [52,53]. In agreement to Sziraki et al., we found that diet induce more appreciable epigenetic changes when the 
low-calorie diet is administered in adulthood, suggesting that the primary changes during aging are not linear and that they either accelerate or decelerate according to nutrition and, possibly, biological age [54-56]. More particularly, in line with other previous studies in mice, at old age, it seems that the low-calorie diet can bring DNA methylation pattern near to the levels of those of the young control subjects, as is evident for Polg2 in the blood and heart $[55,56]$. This observation leads us to retain that positive effect of diet in slowing down aging process might be driven, at least in part, by the epigenetic regulation of the methylation of genes in processes relevant for maintaining cellular homeostasis.

The involvement of epigenetics in the regulation of genes involved in mitochondrial fusion/fission and biogenesis processes during lifetime is not specific of rats. Indeed, we recently reported evidence about this in human, wherein individuals of 18-108 years old, displaying different aging phenotypes according to cognitive, functional and psychological parameters, genes involved in fusion and fission dynamics emerged as biomarkers of both chronological and biological aging [57]. Furthermore, this evidence is also in line with our previous results reporting that global DNA methylation status exhibits tissue-specific changes during aging [41]. Although caution is necessary when relating results in animal models with humans, and the correlation between rats and human ages are not unique, the findings of the present and previous studies suggest that the effect of diet on mitochondrial dynamics is more important in the adulthood and at old age.

Results we observed provide further evidence about the positive impact of the low-calorie diet in counteracting aging and suggests for the first time that the epigenetic modification of genes involved in biogenesis might mediate such impact.

Supplementary Materials: The following are available online at http://www.mdpi.com/2072-6643/12/2/460/s1, Figure S1: Nucleotide sequence of the CpG islands and graphical representation of the CpG sites and units, located within Polg, Polg2, Tfam, Fis1 and Opa1, as according to EpiTYPER software. Sequenom CpG sites analyzed are highlighted in red. Figure S2: Expression levels of Polg, Polg2, Tfam1, Fis1 and Opa1 measured in blood, heart, kidney and liver according to age and tissues in rats fed standard or low-calorie diet. mRNA levels are reported as the mean of relative quantification values $(R Q)$, measured in three independent triplicate experiments with Standard Error Mean (SEM). Figure S3: Relative quantification of mtDNA copy number in blood, heart, kidney and liver according to age and tissues in rats fed standard or low-calorie diet. Levels are reported as the mean of relative quantification values, measured in three independent triplicate experiments with Standard Error Mean (SEM). Table S1: Nucleotide sequence, amplicon size, annealing temperature and chromosomal localization of the primers used in the DNA methylation analysis. Table S2: Nucleotide sequence and chromosomal localization of the primer pairs used in gene expression and mtDNA copy number analyses. Table S3: DNA methylation of Polg, Polg2, Tfam1, Fis1 and Opa1 according to age and tissues in rats fed standard or low-calorie diet. Data represent the mean of DNA methylation values of the CpG sites located within the analyzed genes. SD: Standard Deviation; MD: Methylation Differences between standard or low-calorie diet values. Table S4: DNA methylation values of the $\mathrm{CpG}$ sites of each gene according to age and tissues in rats fed standard or low-calorie diet. SD: standard deviation.

Author Contributions: P.D., F.D.R., F.G., M.M., A.C., D.B. and G.P. designed the study; M.M. provided rat tissues; P.D. performed the experiments; F.D.R. performed the statistical analysis; D.B. and G.P. wrote the initial draft; P.D., F.D.R., F.G., M.M., A.C., D.B. and G.P. participated in critical revision and approved the final manuscript before submission. All authors have read and agreed to the published version of the manuscript.

Funding: This research was funded in the frame of the agreement "SOLUZIONI INNOVATIVE PER L'INNALZAMENTO DELLA SALUTE E DELLA SICUREZZA DELLA POPOLAZIONE" with the University of Calabria.

Acknowledgments: The work has been made possible by the collaboration with the nursing homes of SADEL S.p.A (San Teodoro, San Raffaele, Villa del Rosario, A.G.I srl, SAVELLI HOSPITAL, Casa di Cura Madonna dello Scoglio) in the frame of the agreement "SOLUZIONI INNOVATIVE PER L'INNALZAMENTO DELLA SALUTE E DELLA SICUREZZA DELLA POPOLAZIONE” with the University of Calabria.

Conflicts of Interest: The authors have no conflicts of interest to declare.

\section{References}

1. Loeb, L.A.; Wallace, D.C.; Martin, G.M. The mitochondrial theory of aging and its relationship to reactive oxygen species damage and somatic mtDNA mutations. Proc. Natl. Acad. Sci. USA 2005, 102, 18769-18770. [CrossRef] [PubMed] 
2. Kong, Y.; Trabucco, S.E.; Zhang, H. Oxidative stress, mitochondrial dysfunction and the mitochondria theory of aging. Interdiscip. Top. Gerontol. 2014, 39, 86-107. [PubMed]

3. Fischer, F.; Hamann, A.; Osiewacz, H.D. Mitochondrial quality control: An integrated network of pathways. Trends Biochem. Sci. 2012, 37, 284-292. [CrossRef] [PubMed]

4. Jornayvaz, F.R.; Shulman, G.I. Regulation of mitochondrial biogenesis. Essays Biochem. 2010, 47, 69-84.

5. Yu, S.B.; Pekkurnaz, G. Mechanisms Orchestrating Mitochondrial Dynamics for Energy Homeostasis. J. Mol. Biol. 2018, 430, 3922-3941. [CrossRef] [PubMed]

6. Wu, N.N.; Zhang, Y.; Ren, J. Mitophagy, Mitochondrial Dynamics, and Homeostasis in Cardiovascular Aging. Oxid Med. Cell Longev. 2019, 4. [CrossRef] [PubMed]

7. Westermann, B. Mitochondrial fusion and fission in cell life and death. Nat. Rev. Mol. Cell Biol. 2010, 11, 872-884. [CrossRef]

8. Jang, J.Y.; Blum, A.; Liu, J.; Finkel, T. The role of mitochondria in aging. J. Clin. Investig. 2018, 128, 3662-3670. [CrossRef]

9. Mishra, P.; Chan, D.C. Metabolic regulation of mitochondrial dynamics. J. Cell Biol. 2016, 212, 379-387. [CrossRef]

10. Sergi, D.; Naumovski, N.; Heilbronn, L.K.; Abeywardena, M.; O'Callaghan, N.; Lionetti, L.; Luscombe-Marsh, N. Mitochondrial (Dys)function and Insulin Resistance: From Pathophysiological Molecular Mechanisms to the Impact of Diet. Front. Physiol. 2019, 10, 532. [CrossRef]

11. Molina, A.J.; Wikstrom, J.D.; Stiles, L.; Las, G.; Mohamed, H.; Elorza, A.; Walzer, G.; Twig, G.; Katz, S.; Corkey, B.E.; et al. Mitochondrial networking protects beta-cells from nutrient-induced apoptosis. Diabetes 2009, 58, 2303-2315. [CrossRef] [PubMed]

12. Gomes, L.C.; Di, B.G.; Scorrano, L. During autophagy mitochondria elongate, are spared from degradation and sustain cell viability. Nat. Cell Biol. 2011, 13, 589-598. [CrossRef] [PubMed]

13. Las, G.; Serada, S.B.; Wikstrom, J.D.; Twig, G.; Shirihai, O.S. Fatty acids suppress autophagic turnover in beta-cells. J. Biol. Chem. 2011, 286, 42534-42544. [CrossRef]

14. Liesa, M.; Shirihai, O.S. Mitochondrial dynamics in the regulation of nutrient utilization and energy expenditure. Cell Metab. 2013, 17, 491-506. [CrossRef]

15. Hesselink, M.K.; Schrauwen-Hinderling, V.; Schrauwen, P. Skeletal muscle mitochondria as a target to prevent or treat type 2 diabetes mellitus. Nat. Rev. Endocrinol. 2016, 12, 633-645. [CrossRef] [PubMed]

16. Schrauwen, P.; Schrauwen-Hinderling, V.; Hoeks, J.; Hesselink, M.K. Mitochondrial dysfunction and lipotoxicity. Biochim. Biophys. Acta 2010, 1801, 266-271. [CrossRef]

17. Richardson, D.K.; Kashyap, S.; Bajaj, M.; Cusi, K.; Mandarino, S.J.; Finlayson, J.; DeFronzo, R.A.; Jenkinson, C.P.; Mandarino, L.J. Lipid infusion decreases the expression of nuclear encoded mitochondrial genes and increases the expression of extracellular matrix genes in human skeletal muscle. J. Biol. Chem. 2005, 280, 10290-10297. [CrossRef]

18. Sparks, L.M.; Xie, H.; Koza, R.A.; Mynatt, R.; Hulver, M.W.; Bray, G.A.; Smith, S.R. A high-fat diet coordinately downregulates genes required for mitochondrial oxidative phosphorylation in skeletal muscle. Diabetes 2005, 54, 1926-1933. [CrossRef]

19. Hoeks, J.; Hesselink, M.; Russell, A.; Mensink, M.; Saris, W.; Mensink, R.; Saris, W.H.; Mensink, R.P.; Schrauwen, P. Peroxisome proliferator-activated receptor- $\gamma$ coactivator- 1 and insulin resistance: Acute effect of fatty acids. Diabetologia 2006, 49, 2419-2426. [CrossRef]

20. Xu, D.; Jiang, Z.; Sun, Z.; Wang, L.; Zhao, G.; Hassan, H.M.; Fan, S.; Zhou, W.; Han, S.; Zhang, L.; et al. Mitochondrial dysfunction and inhibition of myoblast differentiation in mice with high-fat-diet-induced pre-diabetes. J. Cell. Physiol. 2019, 234, 7510-7523. [CrossRef]

21. Palacios, O.M.; Carmona, J.J.; Michan, S.; Chen, K.Y.; Manabe, Y.; Ward, J.L., III; Goodyear, L.J.; Tong, Q. Diet and exercise signals regulate SIRT3 and activate AMPK and PGC-1alpha in skeletal muscle. Aging 2009, 1, 771-783. [CrossRef] [PubMed]

22. Jheng, H.F.; Tsai, P.J.; Guo, S.M.; Kuo, L.H.; Chang, C.S.; Su, I.J.; Chang, C.R.; Tsai, Y.S. Mitochondrial fission contributes to mitochondrial dysfunction and insulin resistance in skeletal muscle. Mol. Cell. Biol. 2012, 32, 309-319. [CrossRef] [PubMed]

23. Smith, M.E.; Tippetts, T.S.; Brassfield, E.S.; Tucker, B.J.; Ockey, A.; Swensen, A.C.; Anthonymuthu, T.S.; Washburn, T.D.; Kane, D.A.; Prince, J.T.; et al. Mitochondrial fission mediates ceramide-induced metabolic disruption in skeletal muscle. Biochem. J. 2013, 456, 427-439. [CrossRef] [PubMed] 
24. Motawi, T.M.K.; Hashem, R.M.; Rashed, L.A.; El-Razek, S.M.A. Comparative study between the effect of the peroxisome proliferator activated receptor- $\alpha$ ligands fenofibrate and n-3 polyunsaturated fatty acids on activation of 5'-AMP-activated protein kinase- $\alpha 1$ in high-fat fed rats. J. Pharm. Pharmacol. 2009, 61, 1339-1346. [CrossRef]

25. Lanza, I.R.; Blachnio-Zabielska, A.; Johnson, M.L.; Schimke, J.M.; Jakaitis, D.R.; Lebrasseur, N.K.; Jensen, M.D.; Sreekumaran Nair, K.; Zabielski, P. Author informationInfluence of fish oil on skeletal muscle mitochondrial energetics and lipid metabolites during high-fat diet. Am. J. Physiol. Endocrinol. Metab. 2013, 304, E1391-E1403. [CrossRef]

26. Bach, D.; Naon, D.; Pich, S.; Soriano, F.X.; Vega, N.; Rieusset, J.; Laville, M.; Guillet, C.; Boirie, Y.; Wallberg-Henriksson, H.; et al. Expression of Mfn2, the Charcot-Marie-Tooth neuropathy type 2A gene, in human skeletal muscle: Effects of type 2 diabetes, obesity, weight loss, and the regulatory role of tumor necrosis factor alpha and interleukin-6. Diabetes 2005, 54, 2685-2693. [CrossRef]

27. Lionetti, L.; Sica, R.; Mollica, M.P.; Putti, R. High-lard and high-fish oil diets differ in their effects on insulin resistance development, mitochondrial morphology and dynamic behaviour in rat skeletal muscle. Food Nutr. Sci. 2013, 4, 105-112. [CrossRef]

28. Lionetti, L.; Mollica, M.P.; Donizzetti, I.; Gifuni, G.; Sica, R.; Pignalosa, A.; Cavaliere, G.; Gaita, M.; De Filippo, C.; Zorzano, A.; et al. High-lard and high-fish-oil diets differ in their effects on function and dynamic behaviour of rat hepatic mitochondria. PLoS ONE 2014, 9, e92753. [CrossRef]

29. Casanova, E.; Baselga-Escudero, L.; Ribas-Latre, A.; Arola-Arnal, A.; Bladé, C.; Arola, L.; Salvadó, M.J. Epigallocatechin gallate counteracts oxidative stress in docosahexaenoxic acid-treated myocytes. Biochim. Biophys. Acta 2014, 1837, 783-791. [CrossRef]

30. Nisoli, E.; Tonello, C.; Cardile, A.; Cozzi, V.; Bracale, R.; Tedesco, L.; Falcone, S.; Valerio, A.; Cantoni, O.; Clementi, E.; et al. Calorie restriction promotes mitochondrial biogenesis by inducing the expression of eNOS. Science 2005, 310, 314-317. [CrossRef]

31. Lopez-Lluch, G.; Hunt, N.; Jones, B.; Zhu, M.; Jamieson, H.; Hilmer, S.; Cascajo, M.V.; Allard, J.; Ingram, D.K.; Navas, P.; et al. Calorie restriction induces mitochondrial biogenesis and bioenergetic efficiency. Proc. Natl. Acad. Sci. USA 2006, 103, 1768-1773. [CrossRef]

32. Civitarese, A.E.; Carling, S.; Heilbronn, L.K.; Hulver, M.H.; Ukropcova, B.; Deutsch, W.A.; Smith, S.R.; Ravussin, E.; CALERIE Pennington Team. Calorie restriction increases muscle mitochondrial biogenesis in healthy humans. PLoS Med. 2007, 4, e76. [CrossRef] [PubMed]

33. Hancock, C.R.; Han, D.; Higashida, K.; Kim, S.H.; Holloszy, J.O. Does calorie restriction induce mitochondrial biogenesis? A reevaluation. FASEB J. 2011, 25, 785-791. [CrossRef] [PubMed]

34. Khraiwesh, H.; López-Domínguez, J.A.; López-Lluch, G.; Navas, P.; De Cabo, R.; Ramsey, J.J.; Villalba, J.M.; González-Reyes, J.A. Alterations of ultrastructural and fission/fusion markers in hepatocyte mitochondria from mice following calorie restriction with different dietary fats. J. Gerontol. A Biol. Sci. Med. Sci. 2013, 68, 1023-1034. [CrossRef] [PubMed]

35. Sparks, L.M.; Redman, L.M.; Conley, K.E.; Harper, M.; Yi, F.; Hodges, A.; Eroshkin, A.; Costford, S.R.; Gabriel, M.E.; Shook, C.; et al. Effects of 12 months of caloric restriction on muscle mitochondrial function in healthy individuals. J. Clin. Endocrinol. Metabol. 2016, 102, 111-121. [CrossRef]

36. Menshikova, E.V.; Ritov, V.B.; Dube, J.J.; Amati, F.; Stefanovic-Racic, M.; Toledo, F.G.; Coen, P.M.; Goodpaster, B.H. Calorie restriction-induced weight loss and exercise have differential effects on skeletal muscle mitochondria despite similar effects on insulin sensitivity. J. Gerontol. A Biol. Sci. Med. Sci. 2017, 73, 81-87. [CrossRef]

37. Mulvey, L.; Sands, W.A.; Salin, K.; Carr, A.E.; Selman, C. Disentangling the effect of dietary restriction on mitochondrial function using recombinant inbred mice. Mol. Cell. Endocrinol. 2017, 455, 41-53. [CrossRef]

38. Ruetenik, A.; Barrientos, A. Dietary restriction, mitochondrial function and aging: From yeast to humans. Biochim. Biophys Acta. 2015, 1847, 1434-1447. [CrossRef]

39. Soultoukis, G.A.; Partridge, L. Dietary Protein, Metabolism, and Aging. Annu Rev. Biochem. 2016, 85, 5-34. [CrossRef]

40. Cummings, N.E.; Lamming, D.W. Regulation of metabolic health and aging by nutrient-sensitive signaling pathways. Mol. Cell Endocrinol. 2017, 455, 13-22. [CrossRef] 
41. Guarasci, F.; D'Aquila, P.; Mandalà, M.; Garasto, S.; Lattanzio, F.; Corsonello, A.; Passarino, G.; Bellizzi, D. Aging and nutrition induce tissue-specific changes on global DNA methylation status in rats. Mech Ageing Dev. 2018, 174, 47-54. [CrossRef] [PubMed]

42. Gensous, N.; Franceschi, C.; Santoro, A.; Milazzo, M.; Garagnani, P.; Bacalini, M.G. The Impact of Caloric Restriction on the Epigenetic Signatures of Aging. Int. J. Mol. Sci. 2019, 20, 2022. [CrossRef] [PubMed]

43. Taormina, G.; Russo, A.; Latteri, M.A.; Mirisola, M.G. Mitochondrion at the Crossroad Between Nutrients and Epigenome. Front. Endocrinol. (Lausanne) 2019, 4. [CrossRef]

44. Quiros, P.M.; Goyal, A.; Jha, P.; Auwerx, J. Analysis of mtDNA/nDNA Ratio in Mice. Curr. Protoc. Mouse Biol. 2017, 7, 47-54. [CrossRef]

45. Ibebunjo, C.; Chick, J.M.; Kendall, T.; Eash, J.K.; Li, C.; Zhang, Y.; Vickers, C.; Wu, Z.; Clarke, B.A.; Shi, J.; et al. Genomic and proteomic profiling reveals reduced mitochondrial function and disruption of the neuromuscular junction driving rat sarcopenia. Mol. Cell Biol. 2013, 33, 194-212. [CrossRef]

46. Picca, A.; Pesce, V.; Fracasso, F.; Joseph, A.M.; Leeuwenburgh, C.; Lezza, A.M. Aging and calorie restriction oppositely affect mitochondrial biogenesis through TFAM binding at both origins of mitochondrial DNA replication in rat liver. PLOS ONE 2013, 8, e74644. [CrossRef]

47. Chistiakov, D.A.; Sobenin, I.A.; Revin, V.V.; Orekhov, A.N.; Bobryshev, Y.V. Mitochondrial aging and age-related dysfunction of mitochondria. Biomed. Res. Int. 2014, 2014, 238463. [CrossRef]

48. Sun, N.; Youle, R.J.; Finkel, T. The mitochondrial basis of aging. Mol. Cell. 2016, 61, 654-666. [CrossRef]

49. Kauppila, T.E.S.; Kauppila, J.H.K.; Larsson, N.G. Mammalian mitochondria and aging: An update. Cell Metab. 2017, 25, 57-71. [CrossRef]

50. Srivastava, S. The Mitochondrial Basis of Aging and Age-Related Disorders. Genes 2017, 8, 398. [CrossRef]

51. Barazzoni, R.; Short, K.R.; Nair, K.S. Effects of aging on mitochondrial DNA copy number and cytochrome c oxidase gene expression in rat skeletal muscle, liver, and heart. J. Biol. Chem. 2000, 275, 3343-3347. [CrossRef] [PubMed]

52. Steffann, J.; Pouliet, A.; Adjal, H.; Bole, C.; Fourrage, C.; Martinovic, J.; Rolland-Galmiche, L.; Rotig, A.; Tores, F.; Munnich, A.; et al. No correlation between mtDNA amount and methylation levels at the CpG island of POLG exon 2 in wild-type and mutant human differentiated cells. J. Med. Genet. 2017, 54, 324-329. [CrossRef] [PubMed]

53. Kelly, R.D.; Mahmud, A.; McKenzie, M.; Trounce, I.A.; St John, J.C. Mitochondrial DNA copy number is regulated in a tissue specific manner by DNA methylation of the nuclear-encoded DNA polymerase gamma A. Nucleic Acids Res. 2012, 40, 10124-10138. [CrossRef] [PubMed]

54. Sziráki, A.; Tyshkovskiy, A.; Gladyshev, V.N. Global remodeling of the mouse DNA methylome during aging and in response to calorie restriction. Aging Cell 2018, 17, e12738. [CrossRef]

55. Cole, J.J.; Robertson, N.A.; Rather, M.I.; Thomson, J.P.; McBryan, T.; Sproul, D.; Wang, T.; Brock, C.; Clark, W.; Ideker, T.; et al. Diverse interventions that extend mouse lifespan suppress shared age-associated epigenetic changes at critical gene regulatory regions. Genome Biol. 2017, 18, 58. [CrossRef]

56. Hahn, O.; Grönke, S.; Stubbs, T.M.; Ficz, G.; Hendrich, O.; Krueger, F.; Andrews, S.; Zhang, Q.; Wakelam, M.J.; Beyer, A.; et al. Dietary restriction protects from age-associated DNA methylation and induces epigenetic reprogramming of lipid metabolism. Genome Biol. 2017, 18, 56. [CrossRef]

57. D'Aquila, P.; Montesanto, A.; De Rango, F.; Guarasci, F.; Passarino, G.; Bellizzi, D. Epigenetic signature: Implications for mitochondrial quality control in human aging. Aging (Albany NY) 2019, 11, 1240-1251. [CrossRef]

(C) 2020 by the authors. Licensee MDPI, Basel, Switzerland. This article is an open access article distributed under the terms and conditions of the Creative Commons Attribution (CC BY) license (http://creativecommons.org/licenses/by/4.0/). 